\title{
Avaliação da conformidade físico-química e microbiológica da água tratada e distribuída no município de Santana/AP
}

Um dos principais déficits de serviços de saneamento básico brasileiro, especialmente na região Norte, é a frequente não-conformidade de qualidade da água tratada e distribuída. O objetivo desta investigação é avaliar indicadores físico-químicos e microbiológicos da água ofertada no município de Santana, o 2o mais importante do Estado do Amapá-AP. A metodologia consistiu em monitorar 15 sítios usando amostras de água de consumo humano, aleatoriamente espacializados, com frequência amostral bimestral durante 24 meses. Os parâmetros avaliados foram: $\mathrm{pH}$, Turbidez, $\mathrm{Fe}, \mathrm{NO} 3, \mathrm{Mg}, \mathrm{F}, \mathrm{NH} 3$, Al, Coliformes Totais (CT) e Escherichia coli (EC). As amostras foram coletadas exclusivamente em domicílios servidos pela Companhia de Água e Esgoto do Amapá (CAESA). Os resultados das análises foram comparados com padrões da Portaria $\mathrm{N}^{\circ}$ 2914/2011 do Ministério da Saúde. Exceto F, NO3 e NH3, todos os demais apresentaram não-conformidade em relação a legislação vigente ( $\mathrm{pH}=100 \%$, Turbidez $=57 \%, \mathrm{Fe}=71,4 \%, \mathrm{Mn}=28,5 \%$ e $\mathrm{Al}=100 \%, \mathrm{CT}=100 \%$ e Ecoli $=57,1)$. Testes estatísticos (PCA e Friedman- $\chi 2, \mathrm{p}<0,05$ ) confirmam a hipótese de significativa variação espaço-sazonal físico-química e microbiológica da qualidade da água na malha urbana de Santana-AP. Concluímos, portanto, que a produção e a distribuição da água da CAESA estão comprometidas, necessitando de ajustes e adequação às normas e legislações vigentes no Brasil.

Palavras-chave: Saneamento Urbano; Região Norte; Monitoramento; Série Temporal.

\section{Physico-chemical and microbiological legal compliance assessment of treated and distributed water in the municipality of Santana/AP}

\begin{abstract}
One of the main deficits of Brazilian basic sanitation services, especially in the North region, is the frequent non-conformity of treated and distributed water quality. The objective of the research is to evaluate physical-chemical and microbiological indicators of the supply water available in the municipality of Santana, the 2nd most important in the State of Amapá-AP. The methodology consisted in monitoring 15 urban households using samples of water of human consumption, randomly spatialized. The sampling frequency was bimonthly for 24 months. The water quality parameters evaluated were: $\mathrm{pH}$, Turbidity, $\mathrm{Fe}, \mathrm{NO} 3, \mathrm{Mg}, \mathrm{F}, \mathrm{NH} 3, \mathrm{Al}, \mathrm{CT}$ and EC. Samples were collected exclusively in households served by the Amapá Water and Sewage Company (CAESA). The results were compared to the legal standards (No.2914/2011 of the Ministry of Health-MS). Except for $\mathrm{F}, \mathrm{NO} 3$ and NH3, all others parameters presented non-compliance (\%) with legislation ( $\mathrm{pH}=100 \%$, Turbidity $=57 \%$, $\mathrm{Fe}=71.4 \%, \mathrm{Mn}=28.5 \%, \mathrm{Al}=100 \%, \mathrm{CT}=100 \%$ e Ecoli=57,1\%). Statistical tests (PCA and Friedman- $\chi 2, \mathrm{p}<0.05$ ) confirm the hypothesis of significant physical-chemical and microbiological variation of water quality in the urban network of Santana City-AP. We conclude that the water supply's production and distribution of CAESA are depreciated and need adjustments/adaptation to the norms and laws in force in Brazil.
\end{abstract}

Keywords: Urban Sanitation; North Region; Monitoring; Temporal.

Topic: Engenharia Sanitária

Reviewed anonymously in the process of blind peer

Rafael Neri Furtado

Universidade Federal do Amapá, Brasil

http://lattes.cnpq.br/0114226287592171

rafael_neri.17@hotmail.com

Helenilza Ferreira Albuquerque Cunha

Universidade de São Paulo, Brasil

http://lattes.cnpq.br/3443290397582063

helenilzacunha@gmail.com

Geison Carlos Xisto da Silva

Universidade Federal do Amapá, Brasil

http://lattes.cnpq.br/8305180102641412

geison@unifap.br

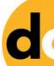

DOI: 10.6008/SPC2179-6858.2017.004.0009
Received: 08/07/2017

Approved: 08/10/2017

Alan Cavalcanti da Cunha

Universidade de São Paulo, Brasil

http://lattes.cnpq.br/2181817533284030

alancunha12@gmail.com

Referencing this:

FURTADO, R. N.; CUNHA, H. F. A.; SILVA, G. C. X.; CUNHA, A. C.. Avaliação da conformidade físico-química e microbiológica da água tratada e distribuída no município de Santana/AP. Revista IberoAmericana de Ciências Ambientais, v.8, n.4, p.101-110, 2017. DOI: http://doi.org/10.6008/SPC2179-6858.2017.004.0009 


\section{INTRODUÇÃO}

O saneamento básico brasileiro deve garantir saúde, segurança e bem-estar da população, evitando as ameaças decorrentes da presença de contaminantes, detritos, resíduos, patógenos ou substâncias tóxicas em geral (IBGE, 2011). Contudo, o cumprimento desta função deve considerar a qualidade das redes e dos serviços básicos oferecidos à população, sem a qual repercutem no nível de eficiência e resposta à demanda desse setor.

Na Região Norte, o Estado do Amapá/AP detém comparativamente uma baixa porcentagem de cobertura de saneamento, comprometendo tanto a qualidade de vida da população quanto o meio ambiente. Por exemplo, aproximadamente $76 \%$ da água de abastecimento e distribuída pela companhia estadual (CAESA) têm sido desperdiçadas (BRASIL, 2013). Este indicador insere o Amapá como o primeiro do ranking nacional, significativamente acima da média nacional, de 63\%. Mas este não é o principal problema, porque além do desperdício quantitativo, estima-se que há também sérios problemas com a qualidade.

Por outro lado, a água para consumo humano com boa qualidade, está intimamente vinculada com qualidade de vida da população (ZULPO et al., 2006; XIONG et al., 2007; CUNHA et al., 2012; SOUZA et al., 2013; YAMAGUCHI, 2013; TONANI et al., 2013; SAIDELLES et al., 2014; PEIL, et al., 2015). E, para que este vínculo saudável seja assegurado, é necessária realizar o monitoramento constante, e com o máximo alcance geográfico possível (CUNHA et al., 2008; CUNHA et al., 2011; COSTA et al., 2011). O objetivo é disponibilizar indicadores e diagnosticar o comportamento espaço-temporal da água tratada e sua qualidade servida à população em suas residências.

O monitoramento frequente da qualidade da água é também importante para identificar potenciais ameaças à saúde humana, possibilitando formas de intervenção, controle e prevenção, visando sua conformidade e os padrões estabelecidos como ideais para o consumo humano (SAIDELLES, et al., 2014). A caracterização físico-química e microbiológica tem por finalidade ser mais uma condicionante legal (BRASIL, 2006; 2011; 2014; 2015), servindo como identificadora de elementos/substâncias presentes associadas à potenciais efeitos de suas propriedades à saúde pública (CUNHA et al., 2011).

O objetivo da presente investigação é analisar o comportamento espaço-sazonal de alguns parâmetros físico-químicos e microbiológicos relevantes de água em 15 residências da área urbana de Santana-AP. O estudo preenche algumas lacunas de conhecimentos sobre o saneamento básico deste município, para diagnosticar o comportamento da variação da qualidade da água e os serviços prestados pela CAESA durante o período de 2012/2014. Os parâmetros escolhidos seguiram o critério de serem facilmente obtidos e utilizados em estudos comparativos e exigidos por legislação.

\section{MATERIAIS E MÉTODOS}

\section{Área de estudo}

O estudo foi realizado na área urbana do município de Santana, localizado ao Sul do Estado do Amapá, a $23 \mathrm{~km}$ distante da capital Macapá. A população estimada é de 113.854 habitantes (IBGE, 2016) e 21.379 
domicílios servidos com abastecimento de água (SIAB, 2013), a partir do qual um mapa específico foi utilizado como base para a aleatorização dos 15 sítios amostrais dentro da área urbana (BioEstat 5.0) (Figura 1).

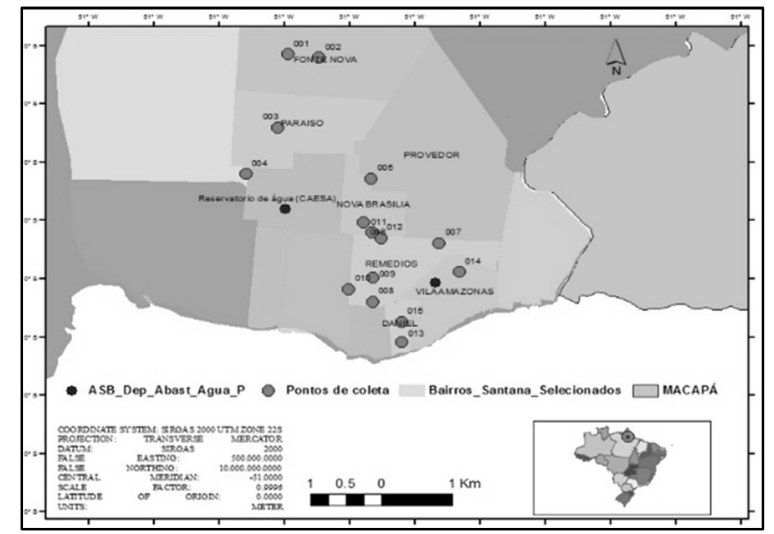

Figura 1: Localização dos pontos de monitoramento da água no município de Santana/AP.

\section{Amostragem por ponto de estudo e coleta do material}

O período de estudo foi de 24 meses, com frequência bimestral de coleta de água nos 15 domicílios, entre dezembro de 2012 e junho de 2014. A amostragem espacial também considerou a categoria de classificação e tipologia de bairros e residências. O esforço amostral e a série temporal total nos dois anos foi $\mathrm{n}=150$ amostras (Figura 1). Em Santana a captação de água ocorre diretamente do rio Amazonas (ETA) e de alguns poços subterrâneos que abastecem a estação central de tratamento do município, ilustrado na figura 1.

Após as coletas in situ, no laboratório, as amostras de água foram preservadas e sua qualidade química determinada de acordo a metodologia padrão (APHA, 2003). Na determinação das concentrações dos metais $\mathrm{Fe}$, Al e $\mathrm{Mn}$, a amostra foi acondicionada em garrafas plásticas, e lavadas com água destilada para a preservação de suas características químicas. Mas antes das análises físico-químicas e microbiológicas as torneiras das residências foram desinfetadas com solução de álcool iodado (2\%), onde sofreram processo de pulverização e higienização por dentro e por fora.

Posteriormente, deixava-se correr água por alguns instantes e preenchia-se os volumes das amostras coletadas em garrafas plásticas de $250 \mathrm{ml}$, lavadas com água destilada. Para análises dos parâmetros microbiológicos, as amostras foram acondicionadas em bolsas estéreis (Thio-bag) com capacidade para $100 \mathrm{~mL}$ de amostra.

\section{Análises físico-químicas e microbiológicas}

Os procedimentos analíticos foram realizados no Laboratório de Química, Saneamento e Modelagem Ambiental do Curso de Ciências Ambientais da Universidade Federal do Amapá (UNIFAP), em duplicatas, para maior confiabilidade de resultados. Os parâmetros determinados seguiram as seguintes metodologias: $\mathrm{pH}$, pelo método potenciométrico, com auxílio de um pHmetro; frações de $\mathrm{N}\left(\mathrm{NO}^{3-}\right)$, pelo método $\mathrm{NitraVer}^{\circledR}$; fluoreto, pelo método SPADNS ${ }^{\circledR}$; ferro, pelo método FerroVer $^{\circledR}$; manganês, pelo método PAN; alumínio, pelo método AluVer ${ }^{\oplus}$; amônia $\left(\mathrm{NH}_{3}{ }^{+}\right)$determinado usando reagente Nessler, todos com o uso de 
espectrofotômetro HACH/DR 2800; turbidez determinado pelo método turbidimétrico, com o uso de um turbidímetro portátil HACH $2100 \mathrm{P}$.

Os parâmetros microbiológicos, Coliformes Totais e Escherichia coli (E. coli), foram determinados pelo método do substrato cromogênico (definido), utilizando reagente COLILERT/IDEXX. Foi adicionado para cada amostra um flaconete de substrato. Após a diluição do substrato, a amostra foi transferida para uma cartela estéril e fechada com auxílio da seladora Quanti-Tray Sealer (CUNHA et al., 2008; 2012). Os resultados foram comparados de acordo com os estabelecidos pela Portaria nํ2914 de dezembro de 2011 do Ministério da Saúde.

\section{RESULTADOS E DISCUSSÃO}

Na tabela 1 são apresentados os resultados para cada um dos parâmetros físico-químicos dos domicílios durante a série de campanhas de campo de 2012/2014. $\mathrm{NO}_{3}, \mathrm{NH}_{3}$ e $\mathrm{F}$ apresentaram conformidade com o estabelecido pela legislação vigente. Contudo, $\mathrm{F}$ esteve ausente em algumas amostras, mas nenhuma infringiu o nível estabelecido pela legislação.

Tabela 1: Resultados físico-químicos de acordo com bairros estudados.

\begin{tabular}{|l|l|l|l|l|}
\hline Parâmetro & VMP/Portaria MS* & $\begin{array}{l}\text { Dentro } \\
\text { do Padrão }\end{array}$ & $\begin{array}{l}\text { Fora } \\
\text { do Padrão }\end{array}$ & Resultado \\
\hline $\mathrm{NO}_{3}$ & $10 \mathrm{mg} / \mathrm{L}$ & $100 \%$ & - & Conformidade \\
\hline $\mathrm{NH}_{3}$ & $1,5 \mathrm{mg} / \mathrm{L}$ & $100 \%$ & - & Conformidade \\
\hline Fluoreto (F) & $1,5 \mathrm{mg} / \mathrm{L}$ & $100 \%$ & - & Conformidade \\
\hline $\mathrm{pH}$ & $6,0-9,5$ & - & $100 \%$ & Não-Conformidade \\
\hline Turbidez & $5 \mathrm{uT}$ & $42,9 \%$ & $57,1 \%$ & Não-Conformidade \\
\hline $\mathrm{Fe}$ & $0,3 \mathrm{mg} / \mathrm{L}$ & $28,6 \%$ & $71,4 \%$ & Não-Conformidade \\
\hline $\mathrm{Mn}$ & $0,1 \mathrm{mg} / \mathrm{L}$ & $71,5 \%$ & $28,5 \%$ & Não-Conformidade \\
\hline $\mathrm{Al}$ & $0,2 \mathrm{mg} / \mathrm{L}$ & - & $100 \%$ & Não-Conformidade \\
\hline
\end{tabular}

Legenda: *Valor Máximo Permitido pela Portaria do Ministério da Saúde (MS)

A aplicação de flúor na água para consumo humano serve para prevenir a cárie dental, tornando-se um processo normal de tratamento de água. O teor ótimo de flúor é parte essencial de sua qualidade (SOUZA, 2013). O processo de fluoretação não é obrigatório nas estações de tratamento (ETA), porém, é importante como preventivo de doenças bucais. O fluoreto, quando ingerido por crianças na fase de formação dentária, em altas concentrações, pode acarretar alterações na dentição denominadas de fluorose dentária. Quando em concentrações ótimas, possui atividade anticariogênica (XIONG et al., 2007).

$\mathrm{O}$ pH é considerado parâmetro-chave de controle do processo de coagulação, sendo fundamental no desempenho do processo de tratamento da água por ser um parâmetro de controle da desinfecção (BRASIL, 2006). Na presente pesquisa, o pH apresentou-se fora do padrão preconizado pela legislação em $100 \%$ dos bairros amostrados. Notabiliza-se como ácido em relação à água consumida pela população. Esse problema foi observado espacialmente em toda a malha urbana da cidade. Isto sugere a necessidade de melhorias no controle da ETA e seu monitoramento no sistema de distribuição.

$\mathrm{O}$ baixo $\mathrm{pH}$ da água contribui com aumento da corrosividade, tornando-se um problema quando o sistema de tratamento ou distribuição utiliza sistemas metálicos. Ao longo do período da pesquisa, foi 
observado que a tubulação, em quase todos os pontos, ainda era constituída de material metálico, podendo comprometer ainda mais sua qualidade consumida.

Alguns fatores que explicam a acidez da água é o fato De a ETA/CAESA ter o pH com valor padrão entre 5,4 a 6,0. Quando a água apresenta valores acima de 6,0 é adicionado mais sulfato para diminuição do pH. Outro fator que contribui, segundo Farias (2006), é a característica ácida, muito comum nos rios amazônicos, pela elevada concentração de matéria orgânica. Quanto maior a disponibilidade e quantidade de matéria orgânica, menor é o pH.

Apesar de apresentar conotação mais de aparência e estética do que sanitária, a turbidez da água de abastecimento público deve apresentar valor máximo de 5,0uT (unidade Jackson ou nefelométrica de turbidez) (RICHTER, 2009; CUNHA et al., 2012). Contudo, observou-se que 57,1\% dos bairros estavam em não-conformidade para este parâmetro. Uma explicação é que a condição ambiental do entorno é normalmente precária, tornando as tubulações propensas a rompimentos e gerando possíveis contaminações da água na presença de partículas que comprometam a qualidade das amostras. Mas mesmo que o tratamento convencional com filtros de areia e a manutenção dos reservatórios ocorram na ETA, segundo Peil et al. (2015), as condições de segurança, a falta de manutenção na rede de distribuição e a interrupção do abastecimento, podem gerar riscos adicionais de contaminação na água proveniente destas entradas indesejáveis.

A turbidez também pode influenciar a redução na transparência da água, pela presença de sólidos suspensos (SCHERER et al., 2016), bem como pela presença de matéria orgânica e outras substâncias como $\mathrm{Zn}, \mathrm{Fe}, \mathrm{Mn}$ e areia (COSTA et al., 2011). No presente caso, considera-se que em alguns sítios amostrais e períodos sazonais a turbidez tenha tido também a contribuição proveniente de íons de Fe e Mn.

O Fe quando encontrado em altas concentrações, mesmo não sendo considerado potencialmente tóxico, pode causar alterações na cor da água, manchar utensílios, roupas e causar constantes incrustações, interferindo no sistema de abastecimento (BÁRBARA et al., 2010). Nesta investigação, em 71,4\% dos bairros, este parâmetro apresentou não-conformidade. Os pontos que apresentaram teores de Fe acima do estabelecido estão localizados nos bairros como Vila Amazonas, onde ocorrem reclamações relacionadas à incrustações e manchas em roupas. O Fe apresenta caráter mais estético do que de potabilidade. Contudo, as fontes de água bruta da região podem, também, apresentar valores que excedam os limites da legislação sem que represente riscos à saúde (CUNHA et al., 2012).

O Mn é um elemento associado ao Fe em virtude do seu comportamento geoquímico. E quase sempre ocorrem juntos. O Mn também apresenta problemas organolépticos, causando sabor desagradável à água, manchando roupas e causa risco de desenvolvimento bacteriano (EMBRAPA, 2011). Espacialmente, os bairros Daniel e Vila Amazonas, que representaram $28,5 \%$ dos bairros amostrados, apresentaram alterações significativas $(p<0,05)$. Foi observado que, assim como o Fe, o Mn estava com valores alterados, nos mesmos períodos e locais.

Foram encontradas concentrações de Al em todos os bairros, o que caracteriza a água como fora dos padrões de aceitação, mesmo que no tratamento seja reduzida sua concentração. Assim, tem sido sugerido 
que os padrões do Al sejam mais rigorosos, evitando potenciais ameaças à saúde dos consumidores. Por exemplo, os metais se tornam acumulativos no ser humano ao serem absorvidos, tornando-se um processo prejudicial à saúde, causador de anemia, doença renal e danos neurológicos (TONANI, 2008). O Al, em elevadas concentrações, como observado neste estudo, compromete a qualidade da água, por ser um componente neurotóxico e induzir distúrbios neurológicos, apesar de não constar como obrigatório no monitoramento e na regulamentação brasileira (FREITAS et al., 2001).

As bactérias denominadas coliformes totais (CT) não são causadoras de doenças e a razão da escolha desse grupo de bactérias, é apenas como indicadora de contaminação da água, devendo-se ao fato de sua presença em fezes de animais de sangue quente, bem como apresentar relação direta com o grau de contaminação fecal (E. coli) (BRASIL, 2014). Os coliformes encontram-se amplamente dispersos no meio ambiente, normalmente os micro-organismos têm importância no controle da qualidade da água e a maioria é benéfica. Entretanto, a presença de bactérias do tipo coliformes pode indicar presença de organismos causadores de doenças (RICHTER, 2009). Por esses motivos, os CT e fecais (E. coli) são os indicadores de contaminação mais usados para monitorar a qualidade microbiológica da água nas ETAs. Mas tais coliformes podem ser patogênicos ou não (BETTEGA et al., 2006).

A Portaria $n^{\circ} 2914 / 11$ - MS, como medida preventiva, exige que tanto CT quanto coliformes fecais como Escherichia coli sejam monitorados nas ETAs, uma vez que ocorrendo a contaminação, ações corretivas devem ser providenciadas. A Tabela 2 apresenta os resultados microbiológicos para estes dois parâmetros indicadores.

Tabela 2: Resultados obtidos para as bactérias do grupo coliformes.

\begin{tabular}{|l|l|l|l|l|}
\hline Parâmetro & NMP/100 $\mathbf{~ L}^{*}$ & Dentro do Padrão & Fora do Padrão & Resultado \\
\hline Coliformes Totais & Ausência & - & $100 \%$ & Não-Conformidade \\
\hline Coliformes Termotolerantes & Ausência & $42,9 \%$ & $57,1 \%$ & Não-Conformidade \\
\hline
\end{tabular}

Legenda: *Número Mais Provável por $100 \mathrm{~mL}$ de amostra.

Foi registrada contaminação por CT em $100 \%$ dos bairros. Neste caso, a legislação determina ausência total nas amostras. Contudo, estes valores sugerem a fragilidade sanitária não só dos domicílios, mas também do sistema de distribuição, mesmo em locais próximos da ETA e suas derivações. Devido à falta de água nos domicílios, os consumidores fazem reservas em caixas d'águas, isso leva a manipulação inadequada de recipientes associados com a falta de higiene. Todos estes fatores significam importantes fontes de risco de contaminação, facilitando o surgimento de potenciais doenças de veiculação hídrica (CUNHA, 2008; CUNHA et al., 2012). Medidas adicionais de caráter corretivo deveriam ser tomadas para reduzir os efeitos colaterais de contaminação química e microbiológica durante as manutenções da rede.

Com observações in locu, verificou-se que na maioria dos domicílios não havia hábito de limpeza ao redor, nem próximo de tubulações expostas. A falta de higiene tem sido sugerida como um dos fatores que contribuem para o número elevado de microrganismos encontrados nesta investigação. Portanto, a presença de CT tende a acentuar ainda mais a importância desse grupo de bactérias como indicador de condições higiênico-sanitárias precárias. Representa risco de contração de doenças de veiculação hídrica (MICHELINA et al., 2006). O subgrupo dos coliformes termotolerantes ou fecais é representada principalmente pela 
bactéria Escherichia coli. A ocorrência de E. coli é considerada indicador de contaminação fecal e possível presença de patógenos entéricos (GUERRA et al., 2006).

Na presente investigação verificou-se a ocorrência de $E$. coli em $57,1 \%$ dos bairros. Em campo, em especial nos pontos com não-conformidades, foram encontradas fossas tanto da própria residência quanto da vizinhança muito próximas de tubulações de água. Algumas a menos de $20 \mathrm{~m}$ de distância, muito abaixo do ideal. Além disso, algumas fossas não tinham proteção e eram apenas escavadas na terra, sem o cuidado necessário. A desinformação dos moradores é fator que contribui com a falta de higiene e contaminação da água. Todos os bairros considerados não-conformes apresentam em comum essa proximidade.

De acordo com Finkler et al. (2015) as águas oriundas de mananciais superficiais tornam-se vulneráveis à contaminação devido à facilidade de acesso para o lançamento de efluentes domésticos, em especial em aglomerado urbanos devido ao crescimento desordenado das cidades.

Nos bairros Provedor e Remédios, o esgoto sanitário é despejado no curso d'agua (quintal), tornando potencialmente o consumo de água inadequado ou inseguro, expondo moradores ao risco de doenças infecciosas e parasitárias veiculadas pela água contaminada. Assim, a água pode sofrer contaminação desde seu ponto de origem, no decorrer da sua distribuição e, especialmente, nos reservatórios (YAMAGUCHI, 2013). Por exemplo, estudos afirmam que $25 \%$ das infecções entéricas podem ser atribuídas a três agentes bacterianos e seus diferentes sorotipos: Shigella, Salmonella e Escherichia coli. Portanto, é necessário constante monitoramento microbiológico da qualidade da água, alertando-se os consumidores à sua possível contaminação (ZULPO et al., 2006).

Apesar de apresentar melhor infraestrutura em relação aos demais bairros de Santana, com rede de esgoto e boa condição asfáltica, Vila Amazonas foi o bairro com maior percentual de não-conformidade físico-química e microbiológica. Este bairro possui uma ETA própria, porém é considerada antiga, com sistema isolado e servindo apenas ao próprio bairro. Neste caso, o procedimento utilizado no tratamento segue apenas a cloração e uma rede de tubulação antiga, segundo relatos de moradores do bairro. Além disso, os bairros Nova Brasília, Remédios e Daniel também apresentaram quadro preocupante de qualidade da água.
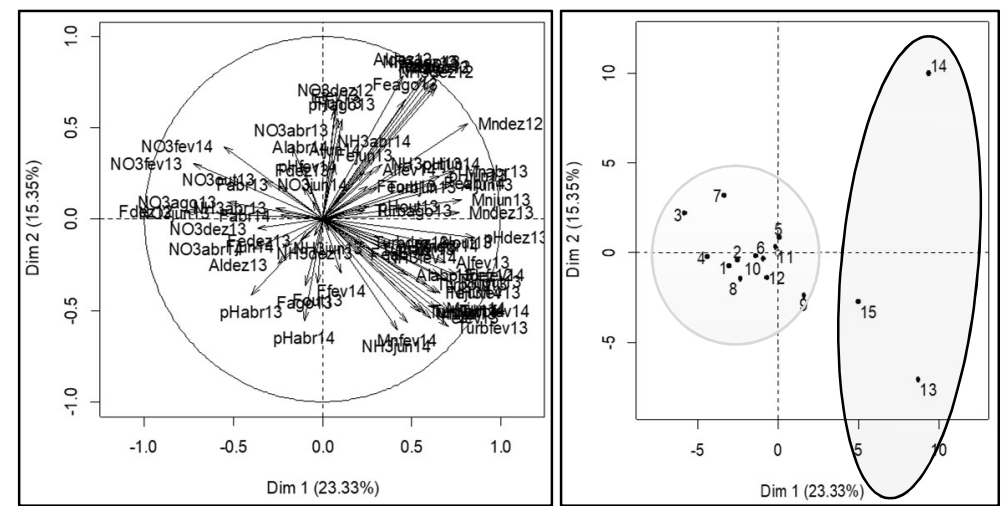

Figura 2: a) Análise Global usando PCA (parâmetro, mês, ano); e b) Análise Global usando PCA (variação espacial). Os números 1-15 representam os domicílios ou bairros estudados (Fonte Nova = 1-2; Paraíso = 3-4; Nova Brasília = 5; Remédios = 6-7; Nova Brasília2 = 8-10; Remédios2 = 11; Provedor = 12; Daniel = 13; Vila Amazonas = 14; Daniel 2 = 15. 
De acordo com as PCAs da figura 2, afirma-se que: o pH apresentou variação espacial significativa (*); a Turbidez não apresentou nenhuma variação espaço-sazonal significativa (NS), assim como o Fe (NS). $\mathrm{O} \mathrm{NO}_{3}$ apresentou apenas variação espacial significativa (*). O Mn apresentou variação espacial/sazonal significativa (*). O F apresentou apenas variação sazonal significativa $(*)$, assim como a NH3 $(*)$. O Al apresentou variação espacial/sazonal significativa $\left({ }^{*}\right)$. O CT apresentou apenas variação espacial significativa $\left({ }^{*}\right)$. Porém, E. coli não apresentou nem variação espacial nem sazonal significativas (NS). Estas análises foram realizadas com o teste não paramétrico Friedman $(p<0,05)$.

Sazonalmente, observa-se uma tendência de deterioração da qualidade da água nos períodos mais chuvosos, também observado em estudos similares no Estado do Amapá. Os parâmetros indicados, por exemplo, na figura 2a, os loadings da PCA projetam-se quase que de forma circular sobre os dois eixos (Dim 1, explicando 23,33\% da variância total e Dim 2, explicando 15,35\% da variância total) incluindo-se todos os parâmetros da qualidade da água. É possível interpretar este comportamento como maior "heterogeneidade sazonal" e maior "homogeneidade" espacial da qualidade da água, nos domicílios de Santana (bairros indicados por números 1-15 na figura $2 b$ ).

Espacialmente, como indicado na Figura 2b, observa-se uma distinção da qualidade da água nas localidades 13, 14 e 15 (círculo azul) em relação aos demais (círculo vermelho), demonstrando que as condições sanitárias destes locais parecem interferir nos níveis de conformidade observadas nas Tabelas 1 e 2.

\section{CONCLUSÕES}

Confirma-se a hipótese de que a água consumida pela população de Santana-AP está com qualidade comprometida, com frequente não-conformidade com a legislação: o consumidor paga por serviços prestados sem a contrapartida da qualidade do atendimento previsto em lei. O bairro Vila Amazonas (14) é o único que conta com rede de esgoto e infraestrutura em relação aos demais. Contudo, os resultados mostraram quase o mesmo nível de não-conformidades em relação aos demais bairros sem infraestrutura. Em alguns casos críticos, tem sido relatado que os moradores utilizam a água da CAESA apenas para serviços domésticos, não incorrendo no "risco" de ingerir água de má qualidade. Isso tem gerado uma série de custos e desperdícios adicionais à já depauperada situação sanitária de Santana.

Apesar de haver previsão de melhorias do sistema de saneamento básico na cidade, o sistema necessita de urgentes providências para melhorar sua qualidade gerencial. Esta pesquisa alerta sobre os riscos sanitários da população sofre e, indiretamente, chama a atenção do Poder Público quanto a este cenário no município de Santana. Por outro lado, não há solução imediata para garantir futuramente a qualidade do serviço de abastecimento de água, a qual, em face da má qualidade da água nos domicílios, está sob risco iminente. 


\section{REFERÊNCIAS}

APHA. American Public Health Association. Standard methods for the examination of water and wastewater. 20 ed. Washington: APHA, 2003.

BÁRBARA, V. F.; CUNHA, A. C.; SIQUEIRA, E. Q.. Monitoramento sazonal da qualidade da água do rio Araguari/AP. Revista de Biociências, Taubaté, v.16, p.57-72, 2010.

BETTEGA, J. M. P. R.; MACHADO, M. R.; PRESIBELLA, M.; BANISKI, G.; BARBOSA, C. A.. Métodos analíticos no controle microbiológico da água para consumo humano. Ciência e Agrotecnologia, v.30, n.5, p.950-954, 2006. DOI: http://doi.org/10.1590/S1413-70542006000500019

BRASIL. Ministério da Saúde. Manual de procedimentos de vigilância em saúde ambiental relacionada à qualidade da água para consumo humano. Brasília: Ministério da Saúde, 2006.

BRASIL. Ministério da Saúde. Portaria n.2914 de 12 de dezembro de 2011. Dispõe sobre os procedimentos de controle e de vigilância da qualidade da água para consumo humano e seu padrão de potabilidade. Brasília, Ministério da Saúde, 2011.

BRASIL. Ministério da Saúde. Sistema de Informação de Atenção Básica: Situação de Saneamento: Brasil. Brasília: Ministério da Saúde, 2013.

BRASIL. Ministério das Cidades. Diagnóstico dos serviços de água e esgotos. Brasília: Ministério das Cidades, 2013.

BRASIL. Ministério do Meio Ambiente. Monitoramento da qualidade da água de rios e reservatórios. Brasília: MMA, 2014.

COSTA, O. L.; KIONKA, D. C. O.; FALEIRO, D. C. C.; KOCH, M. R.; SCHWAMBACH, E.; BERTUZZI, I.; SEIBERT, A. L.; ETHUR, E. M.; OLIVEIRA, E. C.. Análise da qualidade da água de quatro fontes naturais do Vale do taquari/RS. Revista Destaques Acadêmicos, v.4, 2011.

CUNHA, H. F. A.. Geração e avaliação de indicadores de serviços de saneamento em áreas urbanas e suas implicações na qualidade de vida das populações de Macapá e Santana - AP. Monografia (Graduação em Ciências Ambientais) - Universidade Federal do Amapá, Macapá, 2011.

CUNHA, H. F. A.; DUARTE, A. S.; CUNHA, A. C.. Avaliação da qualidade da água mineral utilizada para consumo humano na ótica social e de saúde pública AM Macapá - AP. Macapá: CNPq, 2008.

CUNHA, H. F. A.; LIMA, D. C. I.; BRITO, P. N. F.; CUNHA, A. C.; SILVEIRA JUNIOR,. A. M.; BRITO, D. C.. Qualidade físicoquímica e microbiológica de água mineral e padrões da legislação. Ambi-Agua, Taubaté, v.7, n.3, p.155-165, 2012. DOI: http://doi.org/10.4136/ambi-agua.908

EMBRAPA. Empresa Brasileira de Pesquisa Agropecuária. Manual de procedimentos de amostragem e análise físicoquímica de água. Brasília: EMBRAPA, 2011.
FARIAS, M. S. S.. Monitoramento da qualidade da água na bacia hidrográfica do rio Cabelo. Tese (Doutorado em Engenharia Agrícola) - Universidade Federal de Campina Grande, Campina Grande, 2006.

FINKLER, N. R.; MENDES, L. A.; BORTOLIN, T. A.; SCHNEIDER, V. E.. Cobrança pelo uso da água no Brasil: uma revisão metodológica. Desenvolvimento e Meio Ambiente, v.33, p.33-49, 2015. DOI:

http://doi.org/10.5380/dma.v33i0.36413

FREITAS, M. B.; BRILHANTE, O. M.; ALMEIDA, L. M.. Importância da análise de água para a saúde pública em duas regiões do Estado do Rio de Janeiro: enfoque para coliformes fecais, nitrato e alumínio. Caderno de Saúde Pública, v.17, n.3, p.651-660, 2001.

GUERRA, N. M. M.; OTENIO, M. H.; SILVA, M. E. Z.; GUILERMETTI, M.; NAKAMURA, C. V.; UEDA-NAKAMURA, T.; DIAS FILHO, B. P.. Ocorrência de Pseudomonas aeruginosa em água potável. Acta Scientarum Biological Sciences, v.28, n.1, p.13-18, 2006. DOI:

http://doi.org/10.4025/actascibiolsci.v28i1.1053

IBGE. Instituto Brasileiro de Geografia e Estatística. Atlas de Saneamento. Brasília: IBGE, 2011.

IBGE. Instituto Brasileiro de Geografia e Estatística. IBGE cidades: Santana-Amapá. Brasília: IBGE, 2016.

MICHELINA, A. F.; BRONHAROA, T. M.; DARÉB, F.; PONSANOC, E. H. G.. Qualidade microbiológica de águas de sistemas de abastecimento público na região de Araçatuba, SP. Higiene Alimentar, v.20, n.147, p.90-95, 2006.

PEIL, G. H. S.; KUSS, A. V.; GONÇALVES, M. C. F.. Avaliação da qualidade bacteriológica da água utilizada para abastecimento público no município de Pelotas - RS - Brasil. Ciência e Natura, v.37, n.1, 2015. DOI:

http://doi.org/10.5902/2179460X14941

RICHTER, C. A.. Água: métodos e tecnologia de tratamento.. São Paulo: Editora Blucher/Hemfibra, 2009.

SAIDELLES, A. P. F.; PAIM, R. A.;BENEDETTI, A. C. B. KIRCHNER, R. M.; COPETTI, A. C. C.; MORAES, B. S.. Indicativo sobre possíveis problemas de potabilidade em poços no município de Alegrete - RS. Ciência e Natura, v.36, n.3, p.511- 518, 2014. DOI:

http://doi.org/10.5902/2179460X12835

SCHERER, K.; GRANADA, C. E.; STÜLP, S.; SPEROTTO, R. A.. Avaliação bacteriológica e físico-química de águas de irrigação, solo e alface (Lactuca sativa L.). Ambi-Agua, Taubaté, v.11, n.3, p.66-75, 2016. DOI:

http://doi.org/10.4136/ambi-agua.1829

SOUZA, B. P.; LIMA, L.; LIBÂNIO, M.. Comparação entre a qualidade de água de reservatórios domiciliares e a rede de abastecimento na cidade de Votuporanga-SP. SIMPÓSIO BRASILEIRO DE RECURSOS HÍDRICOS, 20. Anais. Bento Gonçalves: ABRH, 2013.

TONANI, K. A. A.. Identificação e quantificação de metais pesados, parasitas e bactérias em esgoto bruto e tratado na Estação de Tratamento de Esgoto de Ribeirão Preto. 
FURTADO, R. N.; CUNHA, H. F. A.; SILVA, G. C. X.; CUNHA, A. C.

Dissertação (Mestrado em Saúde Pública) - Universidade de São Paulo, Ribeirão Preto, 2008.

XIONG, X.; LIU, J.; HE, W.; XIA, T.; HE, P.; CHEN, X.; YANG, K.; WANG, A.. Dose-effect relationship between drinking water fluoride levels and damage to liver and kidney functions in children. US National Library of Medicine National Institutes of Health, v.103, n.1, p.112-116, 2007. DOI: http://doi.org/10.1016/j.envres.2006.05.008
YAMAGUCHI, M. U.. Qualidade microbiológica da água para consumo humano em instituição de ensino de Maringá-PR. O Mundo da Saúde, v.37, n.3, p.312-320, 2013.

ZULPO, D. L.; PERETTI, J.; ONO, L. M.; GARCIA, J. L.. Avaliação microbiológica da água consumida nos bebedouros da Universidade Estadual do Centro-Oeste, Guarapuava, Paraná, Brasil. Semina: Ciências Agrárias, v.27, n.1, p.107110, 2006. DOI: http://doi.org/10.5433/1679$\underline{0359.2006 \mathrm{v} 27 \mathrm{n} 1 \mathrm{p} 107}$ 